\title{
Cellular response to empty and palladium-conjugated amino-polystyrene nanospheres uptake: A proteomic study
}

\author{
Laura Pietrovito ${ }^{1}$, Victoria Cano-Cortés ${ }^{2}$, Tania Gamberi ${ }^{1}$, Francesca Magherini ${ }^{1}$, \\ Laura Bianchi ${ }^{3}$, Luca Bini ${ }^{3}$, Rosario M. Sánchez-Martín ${ }^{2,4 *}$, Mauro Fasano ${ }^{5}$ \\ and Alessandra Modesti ${ }^{1}$ \\ ${ }^{1}$ Dipartimento di Scienze Biomediche, Sperimentali e Cliniche, Università degli Studi di Firenze, Italy \\ ${ }^{2}$ Department of Medicinal and Organic Chemistry, Faculty of Pharmacy, University of Granada, Granada, Spain \\ ${ }^{3}$ Dipartimento di Scienze della Vita, Università degli Studi di Siena, Italy \\ ${ }^{4}$ GENYO, Centre for Genomics and Oncological Research: Pfizer/University of Granada/Andalusian Regional \\ Government PTS, Granada, Spain \\ ${ }^{5}$ Dipartimento di Scienze Teoriche e Applicate, Biomedical Research Division, Università dell'Insubria, Italy
}

\begin{abstract}
Amino polystyrene nanospheres are shown to be efficient and controllable delivery devices, capable of transporting several bioactive cargoes. Recently, the design of a new device for prodrug activation, using these nanospheres with palladium encapsulated onto them, has been developed successfully. To study the influence of the cellular uptake of these nanodevices, we investigated the cellular response of human embryonic kidney cells (HEK-293T) and murine fibroblasts (L929) treated with empty or palladium-conjugated amino polystyrene nanospheres. To identify differentially expressed proteins, we performed an exhaustive proteomic analysis. In accordance with genomic data previously obtained, the uptake of the empty nanospheres did not induce significant variation in protein expression levels. Following the treatment with palladium-conjugated nanospheres, some changes in protein profiles in both cell lines were observed; these alterations affect proteins involved in cell metabolism and intracellular transport. No key regulator of the cell cycle result was differentially expressed after the treatment, confirming that these innovative drug delivery systems are harmless and well tolerated by the cells.
\end{abstract} Accepted: October 23, 2014

\section{Keywords:}

2DE / Mass spectrometry / Nanospheres / Palladium / Technology

Additional supporting information may be found in the online version of this article at the publisher's web-site

\section{Introduction}

The study of proteome can provide useful information on the types and quantities of proteins produced by a living

Correspondence: Professor Alessandra Modesti, Dipartimento di Scienze Biomediche, Sperimentali e Cliniche, Viale G. Morgagni 5050134 Università degli Studi di Firenze, Italy

E-mail: alessandra.modesti@unifi.it

Fax: +39-055-4598905

Abbreviations: HEK-293T, human embryonic kidney cells; PCA, principal component analysis system in a specific moment, as well as details on the network of protein-protein interactions [1-4]. Concerning the use of proteomic analysis to characterize the cellular response induced by nanospheres treatment, there are few existing studies. The apoptotic/necrotic phenotype observed in human chronic myelogenous leukemia cells incubated with gold nanospheres is mainly due to stress response mediated by unfolded protein associated with endoplasmic reticulum [5].

*Additional corresponding author: Professor Rosario M. SánchezMartín, E-mail: rmsanchez@ugr.es

Colour Online: See the article online to view Figs. 1, 2 and 4 in colour. 
A comparative proteomic study has been reported to identify the signaling pathways leading to oxidative stress in human bronchial epithelial cells induced by titanium dioxide nanospheres [6]. Over the last few decades, interest in drug delivery has been exponentially grown. However, its application in the development of specific and efficient therapies especially in cancer treatment, remains a challenge still open [7]. Encouraging results have been obtained following the synthesis of nanospheres, polymeric matrix in the form of nanosized colloids, that share many characteristics and offer several advantages compared to other drug delivery systems $[8,9]$. Currently, more than 150 different companies are developing nanospheres-based therapeutic products $[10,11]$. In previous studies Sanchez-Martin et al. synthesized monodisperse amino-functionalized polystyrene nanospheres and their cellular uptake successfully demonstrated in a broad range of cell types [12-15]. Relevant cargoes such as proteins, oligonucleotides, both DNA plasmids and siRNA, ion sensors, fluorophores, and metals such as palladium have been conjugated to them and successfully delivered inside cells. Furthermore, by gene-expression profiling studies it was shown that nanospheres did not induce significant alteration of beadfected cell transcriptomes [12]. We have recently developed a method for the selective activation of biomolecules inside living cells using a metal so toxic as palladium (Pd), without inducing cellular death by immobilizing palladium on amino-polysterene nanospheres [16]. The employment of Pd as exogenous catalyst would allow to design highly effective therapeutic platforms devoid of side effects, such as the systemic administration of a pro-drug that is activated only in cells containing Pd nanospheres [17]. Given the many possibilities and applications of nanotechnology, the present project arose from the need to assess side effects induced by treatment with amino-polystyrene nanospheres on cellular functionality. For this purpose, we have chosen human embryonic kidney cells (HEK-293T) and murine fibroblasts (L929) as cell models as they were used previously for geneexpression profiling studies [12]. Following treatment with empty and palladium-conjugated nanospheres, a cell viability study and a proteomic study have been carried out. The significant changes in protein levels of treated cells are very limited. These changes occur mainly in cells treated with Pd-nanospheres. Future studies will be focused on the proteomic analysis of different cancer cells treated with these palladium-nanospheres together with antitumoral prodrugs to go one step closer to in vivo evaluation of this promising therapeutic nanodevice.

\section{Materials and methods}

\subsection{Chemicals and reagents}

Protease inhibitor cocktail, EGTA, Bradford reagent, BSA, DMEM, trypsin/EDTA, FBS, L-glutamine, penicillin/ streptomycin, and PBS were purchased from Sigma-Aldrich
(Saint Louis, MO, USA). Annexin-V-FLUOS Staining Kit was obtained from Roche (Penzberg, Germany).

\subsection{Nanospheres synthesis}

Aminomethyl polystyrene nanospheres (205 and $500 \mathrm{~nm}$ ) were prepared by dispersion polymerization as earlier described [18]. The synthesis of 205 and $500 \mathrm{~nm} \mathrm{Pd}^{0}$-conjugated nanospheres was performed as previously reported [16]. Fluorescent labelling of these nanosphers was done by conjugation of 5(6)-carboxyfluorescein using carbodiimide chemistry protocol already described [16].

\subsection{Cell cultures and beadfection}

Human embryonic kidney cells (HEK-293T) and murine fibroblasts (L929) were provided by the Fundamental Biology Unit of the Center of Scientific Instrumentation of the University of Granada. Cell lines were maintained in DMEM supplemented with $10 \%$ FBS, $4 \mathrm{mM}$ L-glutamine and 1\% v/v penicillin-streptomycin, at $37^{\circ} \mathrm{C}$ and $5 \% \mathrm{CO}_{2}$ humidified atmosphere in a cell culture flask until $70-80 \%$ cell confluence. To beadfection, $2 \times 10^{6}$ HEK-293 and $1 \times 10^{6}$ L929 were seeded in $75 \mathrm{~cm}^{2}$ flasks in growth medium $(15 \mathrm{~mL})$. After one day, the culture media was substituted with fresh medium containing $86 \mu \mathrm{g} / \mathrm{mL}$ empty and Pd-conjugated nanospheres (205 and $500 \mathrm{~nm}$ in diameter). Cells were incubated with nanospheres at $37^{\circ} \mathrm{C}, 5 \% \mathrm{CO}_{2}$ for $48 \mathrm{~h}$. Culture media were not changed during the beadfection. Untreated cells were used as controls.

\subsection{Cellular uptake}

A total of $2.5 \times 10^{5}$ HEK-293T and $1.4 \times 10^{5}$ L929 were seeded in 6-well plates and grown for $24 \mathrm{~h}$ prior to incubation with $86 \mu \mathrm{g} / \mathrm{mL}$ empty and Pd conjugates nanospheres labelled with FITC. After $48 \mathrm{~h}$ of incubation with nanospheres at $37^{\circ} \mathrm{C}$, cells were washed with PBS, harvested by trypsinization, and centrifuged at $2721 \times \mathrm{g}$ for $5 \mathrm{~min}$. Then, the cellular pellets were resuspended in $500 \mu \mathrm{L}$ of PBS and analyzed by flow cytometry using a Becton Dickinson FACScan flow cytometer. Untreated cells and cells treated with naked nanospheres (without fluorescent labeling) were used as controls.

\subsection{Cell viability assay}

The cytotoxic effects of empty and Pd-conjugates nanospheres were assayed by the Annexin-V-FLUOS Staining Kit (Roche). Briefly, HEK-293T and L929 were seeded in 6-well plates $\left(2.5 \times 10^{5}\right.$ and $1.4 \times 10^{5}$ cells/well, respectively) and, after $24 \mathrm{~h}$ of plating, maintained for $48 \mathrm{~h}$ with empty or Pd-conjugates nanospheres $(86 \mu \mathrm{g} / \mathrm{mL})$. After incubation, cells were washed 
once with PBS, detached with trypsin/EDTA and centrifuged at $272 \times \mathrm{g}$ for $5 \mathrm{~min}$. As a positive control of apoptosis, HEK293T and L929, cells treated with $10 \mathrm{mM} \mathrm{H}_{2} \mathrm{O}_{2}$ for $1 \mathrm{~h}$ were used [17]. The stained cells were analyzed on Becton Dickinson FACScan flow cytometer system using $488 \mathrm{~nm}$ excitation and $515 \mathrm{~nm}$ band-pass filter for fluorescein detection and a filter $600 \mathrm{~nm}$ for PI detection. Gating was implemented on the basis of the staining profile of positive controls and of untreated cells (negative control).

\subsection{Samples preparation and 2DE}

HEK-293T and L929 cells were washed once with sterile PBS and lysed with $1 \mathrm{~mL}$ of RIPA buffer $(50 \mathrm{mM}$ Tris- $\mathrm{HCl}$ pH 8.0, $150 \mathrm{mM} \mathrm{NaCl}, 1 \% \mathrm{v} / \mathrm{v}$ Igepal CA-630 (NP-40), $2 \mathrm{mM}$ EGTA, $0.5 \% \mathrm{w} / \mathrm{v}$ sodium deoxycholate and $0.1 \% \mathrm{w} / \mathrm{v}$ SDS, supplemented with a cocktail of protease and phosphatase inhibitors (Sigma) [19]. Protein samples were separated by centrifugation at $8000 \times \mathrm{g}$ for $10 \mathrm{~min}$, then they were isolated by precipitation overnight with five volumes of cold acetone $\left(-20^{\circ} \mathrm{C}\right)$ [20]. After centrifugation at $8000 \times \mathrm{g}$ for $10 \mathrm{~min}$ at room temperature (RT), supernatants containing the interference substances were removed and protein pellets were dried leaving uncapping tubes at RT for $30 \mathrm{~min}$. Dry pellets were redissolved in $8 \mathrm{M}$ urea, $4 \% \mathrm{w} / \mathrm{v}$ CHAPS, $65 \mathrm{mM}$ DTT [19] and protein concentration was determined by Bradford assay in microplate. IEF was performed on IPG strips (BioRad) having $\mathrm{pH}$ 3-10 nonlinear and $18 \mathrm{~cm}$ length by using an Ettan IPGphor ${ }^{\mathrm{TM}}$ system with Ettan IPGphor Manifold $^{\mathrm{TM}}$ (GE Healthcare). Briefly, IPG strips were rehydrated overnight with $350 \mu \mathrm{L}$ of rehydration solution $(8 \mathrm{M}$ urea, $2 \% \mathrm{w} / \mathrm{v}$ CHAPS, $0.5 \% \mathrm{w} / \mathrm{v}$ DTE) supplemented with $0.5 \% \mathrm{v} / \mathrm{v}$ carrier ampholyte (Biorad) and a trace of bromophenol blue by using IPGbox [21]. Then the strips were transferred to Ettan IPGphor Manifold, covered with inert oil. A total of $600 \mu \mathrm{g}$ of protein sample was loaded into the sample cups placed near the anode. The strips were focused at $16^{\circ} \mathrm{C}$ according to the following electrical conditions: $200 \mathrm{~V}$ for $1 \mathrm{~h}, 300 \mathrm{~V}$ for $1 \mathrm{~h}$, from 300 to $3500 \mathrm{~V}$ in $30 \mathrm{~min}, 3500 \mathrm{~V}$ for $4 \mathrm{~h}, 5000$ for $2 \mathrm{~h}$, from 5000 to $8000 \mathrm{~V}$ in $30 \mathrm{~min}$, and $8000 \mathrm{~V}$ until a total of $90000 \mathrm{~V} / \mathrm{h}$ was reached, with a limiting current of $50 \mu \mathrm{A} /$ strip [21]. After IEF, the equilibration steps were performed in $6 \mathrm{M}$ urea, $2 \% \mathrm{w} / \mathrm{v}$ SDS, $2 \% \mathrm{w} / \mathrm{v}$ DTE, $30 \% \mathrm{v} / \mathrm{v}$ glycerol, and $0.05 \mathrm{M}$ Tris-HCL $\mathrm{pH} 6.8$ for $10 \mathrm{~min}$, then in the same buffer containing 2.5\% $\mathrm{w} / \mathrm{v}$ iodoacetamide (IA) in place of DTE, for other $10 \mathrm{~min}$ [21]. The equilibrated strips were placed onto the edge of $9-16 \%$ polyacrylamide linear gradient gels $(18 \mathrm{~cm} \times 20 \mathrm{~cm} \times$ $1.5 \mathrm{~mm}$ ) and covered by $0.5 \% \mathrm{w} / \mathrm{v}$ heated low-melting agarose in SDS electrophoresis running buffer ( $25 \mathrm{mM}$ Tris, $192 \mathrm{mM}$ glycine, $0.1 \% \mathrm{w} / \mathrm{v}$ SDS, pH 8.3) [21]. Second dimension was carried out in a PROTEAN II xi cell gel electrophoresis unit (Bio-Rad) at $10^{\circ} \mathrm{C}$ and at $40 \mathrm{~mA} /$ gel constant current, until the dye front reached the bottom of the gel [21]. Gels were stained following colloidal Coomassie staining protocol [22].

\subsection{Images acquisition and statistical analysis}

We performed three independent biological replicates for each nanosphere type (205 and $500 \mathrm{~nm}$ empty; 205 and $500 \mathrm{~nm}$ Pd conjugated nanospheres), and we carried out two technical replicates (two 2DE) for each sample. Untreated cells were used as controls. Colloidal Commassie-stained gels were digitized using the Epson expression 1680 PRO scanner. The gel images were saved with a resolution of $300 \mathrm{dpi}$ and as 16-bit TIFF format. Image analysis was carried out using the Progenesis SameSpots software version 4.0 (Nonlinear Dynamics, UK) which allows spot detection, background subtraction, and protein spot volume quantification. The gel image showing the highest number of spots and the best protein pattern was chosen as the reference image and its spots were then matched across all gels. This reference image was used to quantify and normalize the spot volumes. The spot volumes were normalized in each gel as relative volume (volume percentage), by dividing the raw quantity of each spot by the total quantity of all the spots included in the reference gel. Statistical analysis was performed using default parameters of the Progenesis SameSpots Stat module. The $\log _{10}$-normalized spot volume was used for the analysis as the $\log$ transformation improves normality. The univariate data analysis was performed as one-way ANOVA $(p<0.05)$ on each spot individually. Principal component analysis (PCA) was performed as multivariate test. The spots with a $p$-value less than 0.05 and with a fold change higher than two were subjected to MS analysis [21]. The spots with a $p$-value less than 0.05 , were subjected to multiple comparisons Tukey's test using Daniel's XL Toolbox version XYZ, an Add-In for Microsoft Excel, by Daniel Kraus (Würzburg, Germany).

\subsection{Protein identification by MS}

The spots of interest were manually excised and destained in a solution with $50 \mathrm{mM}$ ammonium bicarbonate and $50 \% \mathrm{v} / \mathrm{v}$ ACN, then dehydrated in ACN. By using trypsin solution, the spots were rehydrated and digested overnight at $37^{\circ} \mathrm{C}$. Each protein digest $(0.75 \mu \mathrm{L})$ was spotted onto the MALDI target and allowed to air dry. Then $0.75 \mu \mathrm{L}$ of matrix solution (saturated solution of CHCA in $50 \% \mathrm{v} / \mathrm{v}$ ACN and $0.5 \% \mathrm{v} / \mathrm{v}$ TFA) was applied to the sample which was then dried again [23]. Protein identification was carried out using an Ultraflex III MALDI-TOF/TOF mass spectrometer (BrukerDaltonics) equipped with a $200 \mathrm{~Hz}$ smartbeam $^{\mathrm{TM}} \mathrm{I}$ laser. MS analysis was performed in the positive reflector mode according to the following parameters: $80 \mathrm{~ns}$ of delay; ion source 1:25 kV; ion source 2: $21.75 \mathrm{kV}$; lens voltage: $9.50 \mathrm{kV}$; reflector voltage: $26.30 \mathrm{kV}$; and reflector 2 voltage: $14.00 \mathrm{kV}$. The applied laser wavelength and frequency were $353 \mathrm{~nm}$ and $100 \mathrm{~Hz}$, respectively, and the percentage was set to $46 \%$. Final mass spectra were produced by averaging 1500 laser shots targeting five different positions within the spot. Spectra were acquired 
automatically and the Flex Analysis software version 3.0 (Bruker) was used for their analysis and for the assignment of the peaks. The applied software generated a list of peaks up to 200, using a $\mathrm{S} / \mathrm{N}$ of 3 as threshold for peak acceptance. Protein identification by Peptide Mass Fingerprint was performed by uploading data to MASCOT for database searching on the Matrix Science (London, UK, http://www.matrixscience.com) and searched against into UniProtKB protein database (http://www.uniprot.org/). Taxonomy was limited to Homo sapiens or to Mus musculus, mass tolerance set to $100 \mathrm{ppm}$ and one missed cleavage was allowed. Alkylation of cysteine by carbamidomethylation was set as fixed modification, while oxidation of methionine was allowed as variable modification. Search parameters used to accept identifications included the extent of sequence coverage, the number of matched peptides, and a probabilistic score at $p<0.05[19,24]$.

\subsection{Protein validation by Western blot}

Cells were lysated in ice-cold RIPA buffer plus protease and phosphatase inhibitor cocktails for mammalian cells (SigmaAldrich, St. Gallen, CH). A total of $15 \mu \mathrm{g}$ of protein extract were separated by $12 \%$ SDS-PAGE and blotted onto PVDF membrane by using Trans-blot Turbo (Bio-Rad) [19]. Western immunoblottings were performed using a mouse monoclonal antibody against vimentin (Thermo Scientific) diluted 1000 -fold, and a rabbit polyclonal antibody against phosphoglycerate mutase (Abcam, Cambridge, UK) diluted 2000-fold. Anti-mouse (1:2000) and anti-rabbit $(1: 10000)$ peroxidaseconjugated secondary antibodies were purchased from Cell Signaling and TEMA Ricerca, respectively. The reaction was detected with an ECL kit (Thermo Scientific). Quantitative analysis was carried out by densitometric analysis of blotted PVDF, stained with Coomassie brilliant blue R-250, by using Quantity One Software (Bio-Rad) [20]. Statistical analysis was performed by Student's $t$-test and $p$-values lower than 0.05 were evaluated as significant. The intensities of the immunostained bands were normalized with the total protein intensities measured by Coomassie brilliant blue R-250 from the same blot [20].

\section{Results}

\subsection{Evaluation of cellular uptake efficiency and cell viability of Pd conjugated nanospheres}

Uniform aminomethyl polystyrene nanospheres of 205 and $500 \mathrm{~nm}$ of diameter were synthesized by dispersion polymerization from styrene-based monomers and Pd-conjugated nanospheres (205Pd and 500Pd) were prepared following a synthetic procedure previously reported [16]. In order to verify the uptake and toxicity of obtained Pd-conjugated nanospheres, these were incubated for $48 \mathrm{~h}$ with human embryonic kidney cells (HEK-293T) and murine fibroblasts (L929). Following incubation, the cells were detached and analyzed in duplicate by flow cytometry to verify the uptake efficiency. The results, expressed as percentage of fluorescent cells (average of three independent experiments) are reported in the bar plots of Fig. 1A. Concerning HEK-293T cells, 205Pd, 500, and 500Pd nanospheres were internalized with more efficiency than 205 empty nanospheres (70, 82, and $85 \%$ in comparison to $65 \%$, respectively) with a $p$ value less than 0.05. L929 cells are able to internalize with the same efficiency all the four different types of nanospheres. To investigate if nanosphere uptake induces cytotoxicity, we carried out a flow cytometry analysis in order to determine the amounts of viable, apoptotic, or necrotic cells. The results are depicted in Fig. 1B for HEK-293T and 1C for L929 cells. An independent analysis on the two cells lines treated with $10 \mathrm{mM} \mathrm{H}_{2} \mathrm{O}_{2}$ was carried out in order to have a positive control for apoptosis. We used $\mathrm{H}_{2} \mathrm{O}_{2}$ to induce apoptosis because it is an oxygen free radical source able to induce apoptosis in many kinds of cells. As shown in plots, in both cell lines the cell viability is not influenced by the uptake of the different nanospheres. In fact, following 2 days of incubation, more than $90 \%$ of cell population is still viable. The corresponding bar blots show the relative percentages of the different cell populations: alive, early apoptotic, and late apoptotic/necrotic cells for each experimental condition. Either in HEK-293T or L929, the percentages of apoptotic or necrotic cells appear negligible and not significant compared to that of viable cells, underlining that empty and Pd-conjugated nanospheres do not affect viability in these cell lines. Regarding the positive controls for apoptosis, $50 \%$ of the cells show a late apoptotic phenotype.

\subsection{Protein expression profiles of treated HEK-293T and $L 929$ cells}

To investigate in detail the effects induced by the nanosphere uptake on cells, the protein expression profiles were analyzed through comparative proteomic study. Following the incubation, cells were lysed and the protein extracts were separated by 2DE. Overall, 30 gels were analyzed by Progenesis Samespots software for each cell line, in order to reduce the experimental and biological variability, as well as to obtain statistically significant results. Approximately, more than 2000 spots were detected in each colloidal Coomassiestained 2DE gels. All the gels analyzed showed a relatively similar protein pattern, indicating that the treatment with nanospheres affects only partially the proteomic profiles of HEK-293T and L929 cells (Supporting Information Fig. 1).

Between the spots differentially expressed, were considered only the spots statistically significant (ANOVA $\leq 0.05$ ) and with a fold change $\geq 2$. In HEK293T cells the protein expression profiles of 17 proteins were found changed. Among these, five spots $(2,3,5,6$, and 13$)$ resulted more abundant 
A

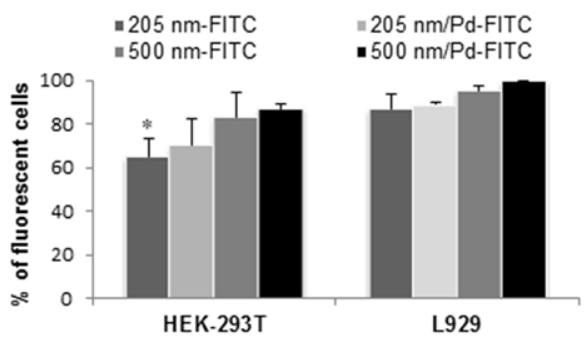

B

$10 \mathrm{mM} \mathrm{H} \mathrm{O}_{2} 2 \quad$ Untreated
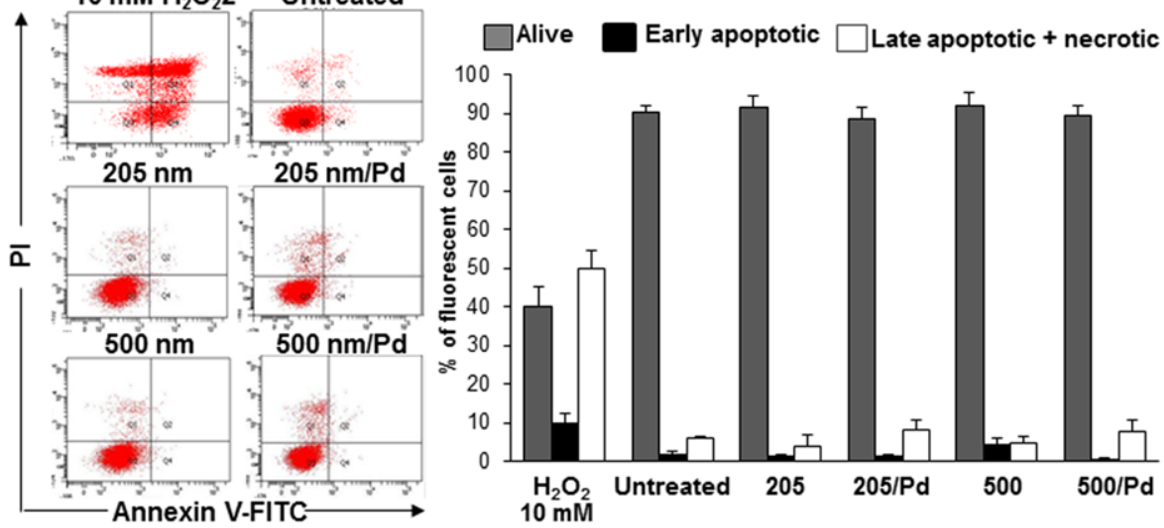

C

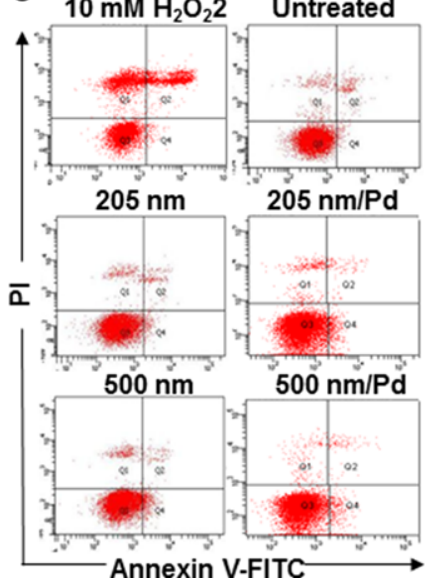

Figure 1. Evaluation of uptake efficiency and cell viability by flow cytometry. (A) Percentage of fluorescent labeled cells after treatment. (*) Indicates a significant difference between the uptake of 205 empty nanospheres and 500 (empty and Pd) nanospheres. ( $B$ and $C$ ) Cells were stained with Annexin-V/Propidium lodide: flow cytometry plots and bar plots show the percentage of viable, early apoptotic, and late apoptotic/necrotic HEK-293T (B) and L929 cells (C) following incubation with the different types of nanospheres for $48 \mathrm{~h}$. and 12 were less abundant. Concerning L929 cells we found increased 24 protein spots compared to controls. Figure 2 reports the locations of these protein spots marked with arrows in the representative gel images. The differences among the $2 \mathrm{D}$-electrophoretic profiles obtained from the five different experimental conditions for each cell type were subjected to a PCA. In the resulting PCA plots (Fig. 2C and D), we observe five different groups, underlining a good reproducibility of data sets. The differences in protein expression profiles are more evident in both cells treated with Pd-conjugated nanospheres. The empty nanospheres groups (205 and 500) are spread very close to the control groups, while the 205Pd and 500Pd are localized in the opposite side of the plots.

\subsection{Identification of protein variations in empty and Pd conjugated nanospheres treated cells}

\subsubsection{Altered Proteins in HEK-293T cells}

Among the 17 protein spots excised from preparative gels, we identified by MS 13 proteins reported in Table 1 . Not all protein spots of interest were identified, both because they are also formed by poorly represented proteins and because MS presents inherent sensitivity limits. The data obtained confirmed that the variations in protein expression profiles occur in cells treated with $205 \mathrm{Pd}$ or $500 \mathrm{Pd}$ in comparison to empty nanospheres and control cells, as previously observed by PCA plots. We found two proteins involved in transcription 
A

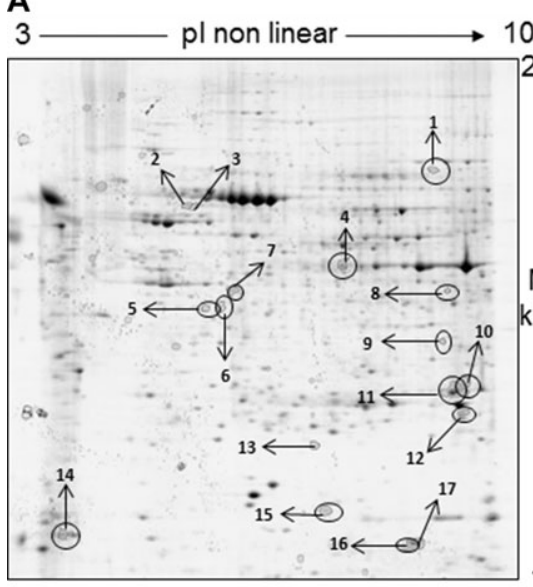

C

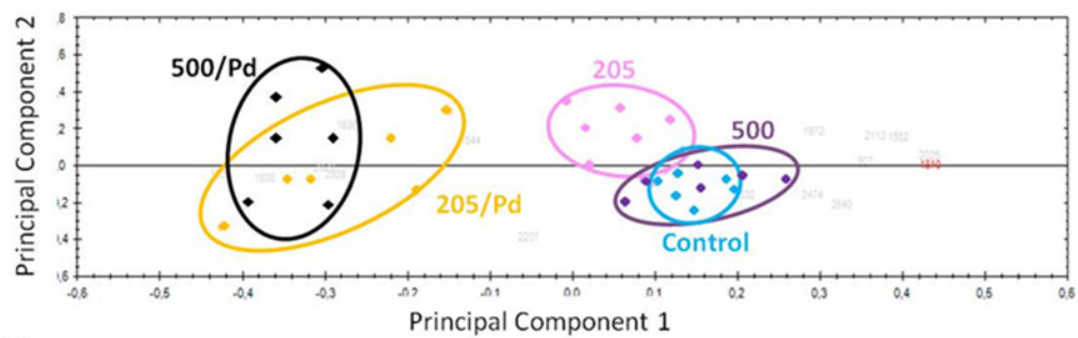

D

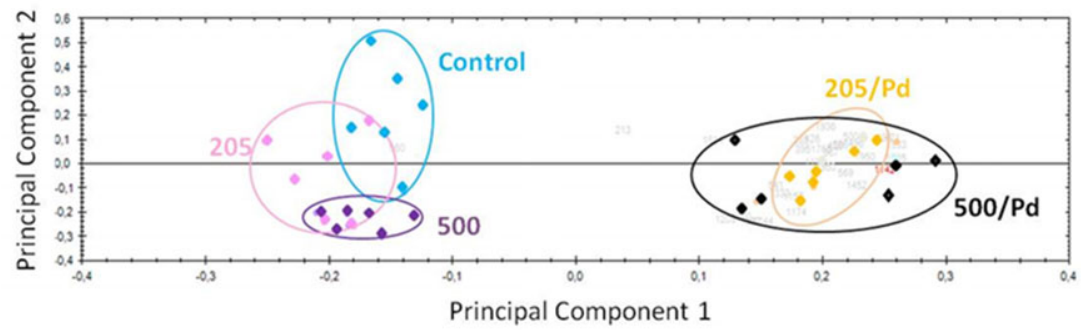

B $3 \longrightarrow$ pl non linear $\longrightarrow 10$

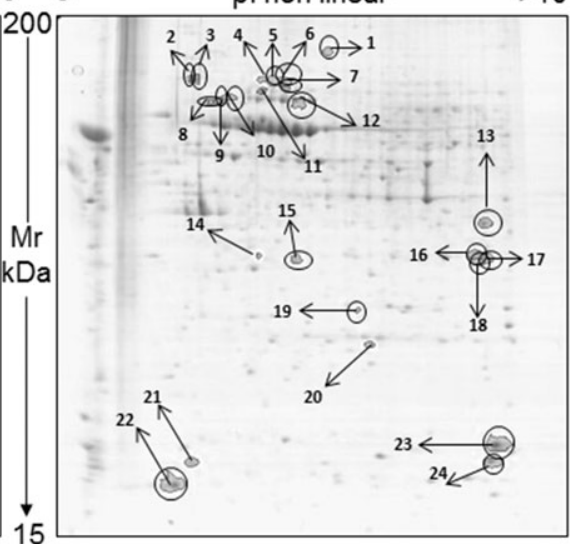

15

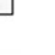


Table 1. Differentially expressed protein spots identified by MALDI-TOF analysis. Search was performed in UniProtKB database using MASCOT software.

\begin{tabular}{|c|c|c|c|c|c|c|c|c|c|c|c|}
\hline $\begin{array}{l}\text { Spot } \\
\text { no }\end{array}$ & Protein name & $A C^{b)}$ & $\begin{array}{l}\text { Theoretical } \\
\mathrm{Mw}(\mathrm{kDa}) / \\
\mathrm{p} / \mathrm{c})\end{array}$ & Score $^{\text {d) }}$ & $\begin{array}{l}\text { No. of } \\
\text { matched } \\
\text { peptides }^{\text {e) }}\end{array}$ & $\begin{array}{l}\text { Sequence } \\
\text { coverage }^{f)}\end{array}$ & Foldg) & $p$-value ${ }^{\mathrm{h})}$ & \multicolumn{3}{|c|}{$\begin{array}{l}\text { Tukey's post } \\
\text { hoc multiple } \\
\text { comparisons }^{i)}\end{array}$} \\
\hline \multicolumn{12}{|c|}{ HEК293Т } \\
\hline 1 & $\begin{array}{l}\text { Far upstream element-binding } \\
\text { protein } 2\end{array}$ & 092945 & $6.8 / 73.11$ & 251 & $18 / 20$ & 34 & -2.2 & $1.2 \mathrm{e}-02$ & & & $\begin{array}{l}C / D \\
C / E\end{array}$ \\
\hline 4 & Mix: Alpha-enolase & P06733 & $7.0 / 47.17$ & 188 & $23 / 56$ & 63 & -2.1 & $2.1 \mathrm{e}-02$ & & & $\mathrm{C} / \mathrm{E}$ \\
\hline 5 & $\begin{array}{l}\text { Beta-enolase } \\
\text { Anamorsin }\end{array}$ & $\begin{array}{l}\text { P13929 } \\
\text { Q6FI81 }\end{array}$ & $\begin{array}{l}7.6 / 46.99 \\
5.4 / 33.58\end{array}$ & $\begin{array}{r}70 \\
191\end{array}$ & $\begin{array}{l}12 / 56 \\
12 / 16\end{array}$ & $\begin{array}{l}31 \\
40\end{array}$ & 2 & $1.2 \mathrm{e}-02$ & $A / D$ & & $C / D$ \\
\hline 6 & $\begin{array}{l}\text { COP9 signalosome complex } \\
\text { subunit } 4\end{array}$ & Q9BT78 & $5.6 / 46.27$ & 199 & $21 / 47$ & 61 & 3.2 & $3.2 \mathrm{e}-02$ & & & \\
\hline 7 & $\begin{array}{l}\text { Quinone oxidoreductase- } \\
\text { like protein } 1\end{array}$ & 095825 & $5.5 / 38.70$ & 102 & $9 / 23$ & 33 & -3.3 & $1.8 \mathrm{e}-02$ & & & \\
\hline 8 & $\begin{array}{l}\text { Nuclear inhibitor of protein } \\
\text { phosphatase } 1\end{array}$ & Q12972 & $6.9 / 38.48$ & 102 & $9 / 24$ & 34 & -2.4 & $4.4 \mathrm{e}-02$ & & & \\
\hline 9 & Pirin & 000625 & $6.4 / 32.11$ & 101 & $9 / 27$ & 38 & -3.3 & $8.9 e-04$ & $A / D$ & & C/D \\
\hline 10 & $\begin{array}{l}\text { S-Methyl-5'-thioadenosine } \\
\text { phosphorylase }\end{array}$ & Q13126 & $6.7 / 31.23$ & 114 & $14 / 39$ & 51 & -2.7 & $4.6 e-02$ & & & \\
\hline 11 & Phosphoglycerate mutase 1 & P18669 & $6.7 / 28.80$ & 284 & $17 / 17$ & 75 & -2.7 & $3.0 \mathrm{e}-03$ & $A / D$ & $B / D$ & \\
\hline 12 & Triosephosphate Isomerase & P60174 & $5.6 / 30.79$ & 121 & $14 / 61$ & 58 & -3.2 & $3.5 e-02$ & & & \\
\hline 14 & Myosin light polypeptide 6 & P60660 & $4.6 / 16.93$ & 105 & $11 / 41$ & 68 & -2.5 & $2.6 e-02$ & & & $\mathrm{C} / \mathrm{E}$ \\
\hline 15 & Prefoldin subunit 2 & Q9UHV9 & $6.2 / 16.65$ & 101 & $11 / 32$ & 54 & -2.5 & $1.1 \mathrm{e}-02$ & & & $\mathrm{C} / \mathrm{E}$ \\
\hline 16 & $\begin{array}{l}\text { Histidine triad nucleotide- } \\
\text { binding protein } 1\end{array}$ & P49773 & $6.4 / 13.80$ & 105 & $8 / 14$ & 77 & -2.2 & $3.2 \mathrm{e}-02$ & & & \\
\hline \multicolumn{12}{|c|}{ 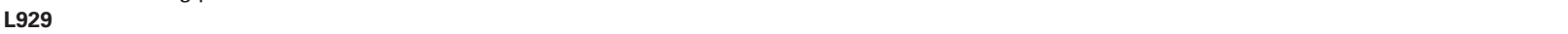 } \\
\hline 1 & Vinculin & Q64727 & $5.8 / 116.72$ & 174 & $19 / 28$ & 22 & 3.7 & $5.4 e-03$ & & & \\
\hline 2 & Vimentin & P20152 & $5.0 / 53.69$ & 118 & $19 / 82$ & 43 & 3.1 & $2.4 \mathrm{e}-03$ & $\mathrm{~A} / \mathrm{E}$ & $\mathrm{B} / \mathrm{E}$ & $\mathrm{C} / \mathrm{E}$ \\
\hline 3 & $\begin{array}{l}\text { Transitional endoplasmic } \\
\text { reticulum ATPase }\end{array}$ & Q01853 & $5.1 / 89.32$ & 201 & $31 / 82$ & 53 & 4.1 & $1.5 e-03$ & $A / E$ & $\mathrm{~B} / \mathrm{E}$ & $\mathrm{C} / \mathrm{E}$ \\
\hline 5 & Gelsolin & $\mathrm{P} 13020$ & $5.1 / 85.94$ & 188 & $23 / 51$ & 36 & 4.8 & $1.5 e-03$ & & $\mathrm{~B} / \mathrm{D}$ & $C / D$ \\
\hline 6 & Gelsolin & P13020 & $5.1 / 85.94$ & 83 & $14 / 48$ & 20 & 7.6 & $4.2 \mathrm{e}-04$ & $A / D$ & $B / D$ & $C / D$ \\
\hline 7 & Gelsolin & $\mathrm{P} 13020$ & $5.1 / 85.94$ & 136 & $19 / 53$ & 35 & 4.9 & $1.1 \mathrm{e}-02$ & & & \\
\hline 8 & $\begin{array}{l}\text { NADH-ubiquinone } \\
\text { oxidoreductase } 75 \mathrm{kDa} \\
\text { subunit, mitochondrial }\end{array}$ & Q91VD9 & $5.5 / 79.78$ & 158 & $17 / 33$ & 30 & 5.3 & $4.8 \mathrm{e}-06$ & $\begin{array}{l}A / D \\
A / E\end{array}$ & $\begin{array}{l}B / D \\
B / E\end{array}$ & $\begin{array}{l}C / D \\
C / E\end{array}$ \\
\hline 9 & $\begin{array}{l}\text { Eukaryotic translation initiation } \\
\text { factor } 4 \mathrm{~B}\end{array}$ & Q8BGD9 & $5.5 / 68.84$ & 137 & $15 / 29$ & 26 & 3.4 & $8.5 e-04$ & & $\begin{array}{l}B / D \\
B / E\end{array}$ & $\begin{array}{l}C / D \\
C / E\end{array}$ \\
\hline 10 & $\begin{array}{l}\text { Heat shock cognate } 71 \mathrm{kDa} \\
\text { protein }\end{array}$ & P63017 & $5.4 / 70.87$ & 267 & $34 / 70$ & 56 & 4.2 & $8.8 e-03$ & & & \\
\hline 12 & Stress-70 protein mitochondrial & P38647 & $5.8 / 73.46$ & 259 & $29 / 50$ & 52 & 4.8 & $6.8 e-03$ & & & \\
\hline 13 & Macrophage-capping protein & P24452 & $6.7 / 39.24$ & 95 & $11 / 32$ & 38 & 4.2 & $2.5 e-03$ & $\begin{array}{l}A / C \\
A / D \\
A / E\end{array}$ & & \\
\hline 15 & $60 \mathrm{~S}$ acidic ribosomal protein $\mathrm{PO}$ & P14869 & $5.9 / 34.22$ & 160 & $14 / 29$ & 56 & 5.5 & $1.1 \mathrm{e}-02$ & & & \\
\hline 16 & $\begin{array}{l}\text { LIM and } \mathrm{SH} 3 \text { domain } \\
\text { protein } 1\end{array}$ & Q61792 & $6.6 / 29.99$ & 172 & $16 / 29$ & 44 & 3.1 & $1.5 \mathrm{e}-03$ & $\begin{array}{l}A / D \\
A / E\end{array}$ & & \\
\hline 17 & $\begin{array}{l}\text { Heterogeneous nuclear } \\
\text { ribonucleoprotein D-like }\end{array}$ & Q3SWU3 & $9.1 / 35.29$ & 104 & $11 / 34$ & 34 & 3.7 & $3.2 \mathrm{e}-04$ & $\begin{array}{l}A / D \\
A / E\end{array}$ & & \\
\hline 18 & Aldose reductase & P45376 & $6.7 / 35.73$ & 195 & $18 / 51$ & 61 & 3.4 & $4.4 e-04$ & $\mathrm{~A} / \mathrm{C}$ & & \\
\hline 19 & $\begin{array}{l}26 \mathrm{~S} \text { proteasome non-ATPase } \\
\text { regulatory subunit } 9\end{array}$ & Q9CR00 & $6.0 / 24.72$ & 107 & $11 / 23$ & 46 & 3.0 & $4.0 \mathrm{e}-02$ & & & \\
\hline 22 & Galectin-1 & P16045 & $5.3 / 14.86$ & 129 & $12 / 44$ & 94 & 5.0 & $1.0 \mathrm{e}-03$ & & & \\
\hline 23 & $\begin{array}{l}\text { Nucleoside diphosphate } \\
\text { kinase B }\end{array}$ & 001768 & 7.0/17.36 & 158 & $15 / 46$ & 73 & 7.3 & $7.6 e-03$ & $A / D$ & & \\
\hline 24 & $\begin{array}{l}\text { Nucleoside diphosphate } \\
\text { kinase A }\end{array}$ & P15532 & $6.8 / 17.21$ & 177 & $15 / 36$ & 80 & 5.7 & $2.8 \mathrm{e}-02$ & $A / D$ & & \\
\hline
\end{tabular}

a) Spot numbers match those reported in the representative Coomassie Colloidal 2DE gels shown in Fig. 2.

b) Accession number in UniProtKB.

c) Predicted MW and $\mathrm{p} /$ in UniProtKB according to protein sequence.

d) Mascot score (matrix Science, London, UK; http://www.matrixscience.com).

e) Number of matched peptides correspond to peptide masses matching the top hit from Ms-Fit PMF.

f) Sequence coverage indicates (number of the identified residues/total number of amino acid residues in the protein sequence) $\times 100$.

g) Fold change was calculated by SameSpot software. It is the ratio between the highest mean normalized volume and the lowest mean normalized volume.

h) ANOVA $p$-value $\leq 0.05$.

i) Tukey's post ANOVA results. Different experimental conditions are indicated with letters: A) Untreated cells; B) incubated with empty 250 $\mathrm{nm} ; \mathrm{C}$ ) incubated empty $500 \mathrm{~nm}$; D) incubated with $205 \mathrm{Pd}$; incubated with $500 \mathrm{Pd}$. 


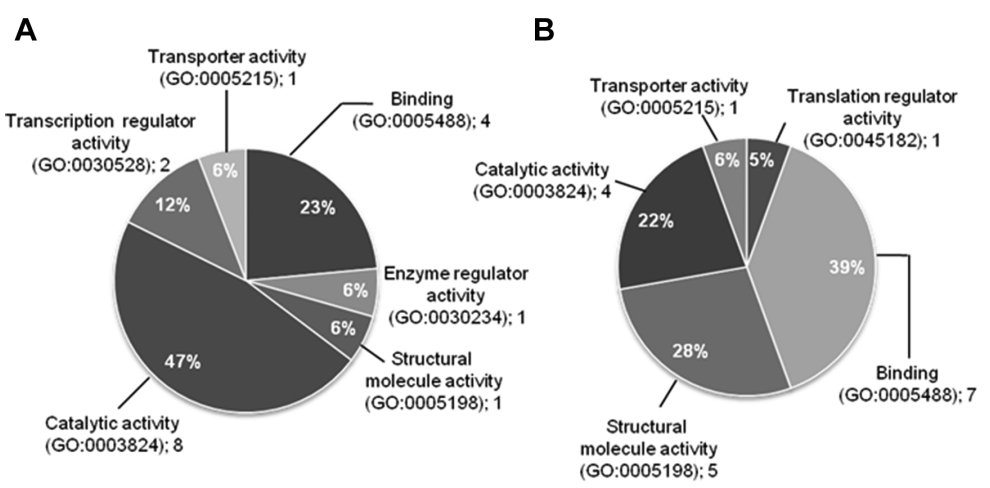

C
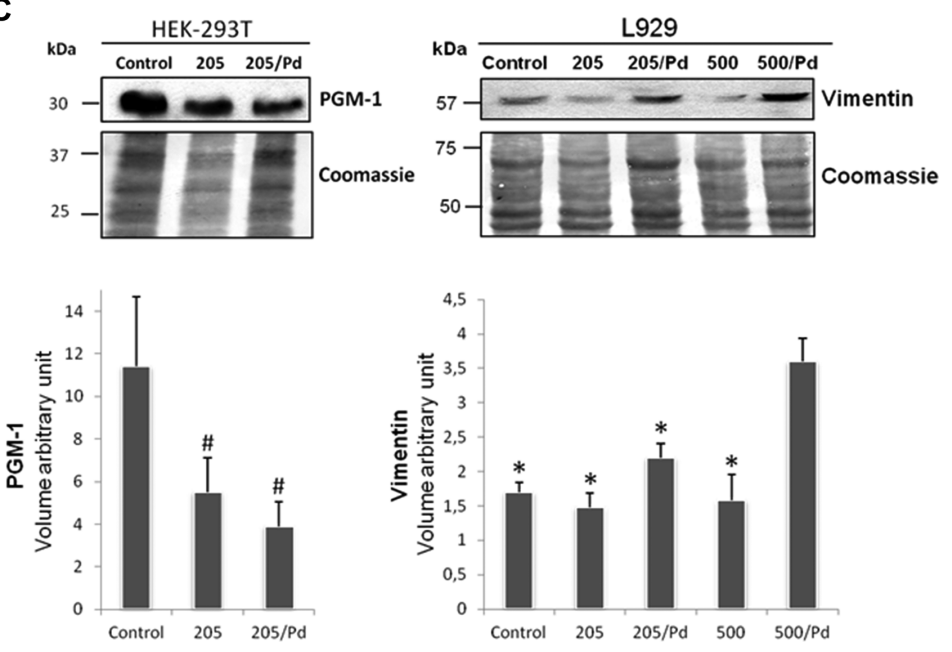

Figure 3. Functional classification and validation of identified proteins. Proteins were classified by Panther software (http://www.pantherdb.org) according to GO classification. (A) HEK-293T and (B) L929 cells. (C) Western blots with anti PGM-1 and anti Vimentin antibodies. The intensity of immunostained bands was normalized against the total protein intensities measured from the same blot stained with Coomassie brilliant blue. (\#) $p$ value $<0.005$ vs control $\left({ }^{*}\right) p$-value $<0.0004$ vs. $500 / \mathrm{Pd}$. are classified and grouped in five categories. Most are involved in "binding," "structural molecule activity," and "catalytic activity." To further validate the proteomic results we assayed the protein expression levels of two selected proteins in total protein extracts from HEK-293T and L929 cells treated with different types of nanospheres in comparison to untreated cells. We decided to validate the proteins involved in the most affected functional categories, such as glycolisis and cytoskeletal remodeling and we selected the proteins phosphoglycerate mutase for HEK-293T cells and vimentin for L929 cells. Their amounts were measured by Western blot analysis. Results, reported in Fig. 3, show that the expression levels of phosphoglycerate mutase (C) and vimentin (D) are significantly changed (less and more abundant, respectively), in cells treated with Pd-conjugated nanospheres in comparison to controls and cells incubated with empty nanospheres.

\subsection{Bioinformatics analysis of proteomic data}

To establish whether the differentially expressed proteins were associated with cellular pathways that were not directly pointed out from the proteomic results, we performed a bioinformatics analysis by using the web-based tool BioProfiling.de
[26]. We separately uploaded two text files, with the 13 and 17 identified proteins, corresponding to the two different cellular systems and we selected Homo sapiens for HEK293T cells and Mus musculus for L929 cells as organisms. Figure 4 summarizes the results obtained for the HEK-293T cells (A) and L929 cells (B) by using R-Spider. This tool analyzes gene/protein list using as reference knowledge a global gene network constructed by combining signaling and metabolic pathways from reactome and KEGG databases [27]. In the tables of Fig. 4 are shown the models' definitions, which specify the maximal allowed distance between two input proteins connected, the number of input proteins covered by the system, and the corresponding significance of the best inferred model. As it is evident in panel A of Fig. 4, the inferred network models D1 and D2 cover three proteins of the 13 used as input with a $p$-value estimated less than 0.005 ; while the model D3 covers four proteins with a $p$-value less than 0.03 . We decided to analyze all these networks and we reported the graphical illustrations of the protein-protein interactions obtained by Cytoscape: http://www.cytoscape.org/ [28]. Since the network models D1 and D2 provided the same results, we reported only the D1 and D3 illustrations. Three proteins, belonging to metabolism of carbohydrates, are connected in network model D1. The network D3 includes two 
A

\begin{tabular}{cc|c|}
\hline $\begin{array}{c}\text { Model } \\
\text { Defenition }\end{array}$ & $\begin{array}{c}\text { TheNumber } \\
\text { of input } \\
\text { genes }\end{array}$ & p-value \\
\hline Model D1 & 3 & $<0.005$ \\
\hline Model D2 & 3 & $<0.005$ \\
\hline Model D3 & 4 & $<0.03$ \\
\hline
\end{tabular}

B

\begin{tabular}{cc|c|}
$\begin{array}{c}\text { Model } \\
\text { Defenition }\end{array}$ & $\begin{array}{c}\text { The Number } \\
\text { of input } \\
\text { genes }\end{array}$ & p-value \\
\hline Model D1 & 1 & $<0.99$ \\
\hline Model D2 & 3 & $<0.03$ \\
\hline Model D3 & 3 & $<0.235$ \\
\hline
\end{tabular}

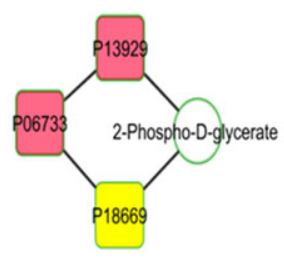

D1 and D2

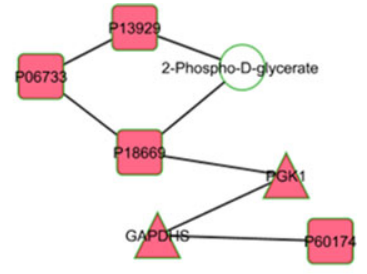

D3

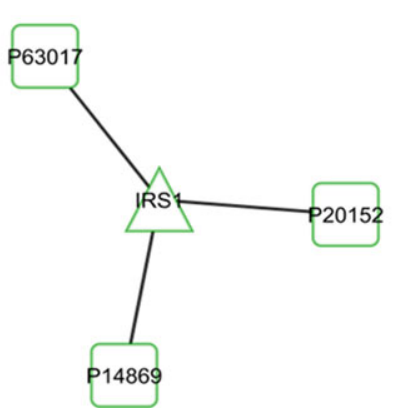

Figure 4. Bioinformatics analysis of differently expressed proteins in response to treatment with empty or Pd-conjugated nanospheres obtained from HEK-293T (A) and $L 929$ cells (B). See manuscript for details. intermediate proteins: glyceraldehydes-3-phosphate dehydrogenase and phosphoglycerate kinase not detected in our proteomic studies. Regarding the L929 cells results, only the model D2 has a significant $p$-value less than 0.03 . The corresponding graphical illustration of the network shows an intermediate protein which is able to bind specifically to various cellular proteins containing SH2 domains.

\section{Discussion}

We demonstrated that the uptake ability using the 205Pd is $20 \%$ higher for L929 cells in comparison to HEK-293T cells, while the ability to internalize the 500Pd is comparable between these two cell lines. The significant changes in protein levels of cell incubated with the nanospheres are very limited and these variations occur in both cell lines treated with Pd-nanospheres in comparison to the empty one. No key protein involved in cell cycle was found differentially expressed between treated and control cells. Only a negative regulator of apoptosis (Anamorsin), results are more abundant in HEK-293T cells following $48 \mathrm{~h}$ of incubation. In the same cellular type we found as less abundant some proteins implicated in transcription and protein folding control and some enzymes involved in glycolysis. L929 cells are more susceptible to nanosphere uptake than human cell line and all identified proteins showed a more abundant expression level after treatment. Among these, most are drawn in intracellular transport: some are structural component of cytoskeleton, others are involved in actin filaments polymerization. All these results corroborate the hypothesis previously proposed according to which the uptake mechanism does not occur by endocytosis, but through rapid cytoskeletal rearrangements based on actin filaments polymerization [12]. Future studies will be focused on the proteomic analysis of different cancer cells treated with Pd-nanospheres together with antitumoral prodrugs, to go one step closer to in vivo evaluation of this promising therapeutic nanodevice.

This research was partially supported by a Marie Curie Career Integration Grants within the 7th European Community Framework Programme (RSM) and by the Ente Cassa di Risparmio di Firenze 2013-0682 MICROPRO (LP). We want to thank Gustavo Ortiz Ferrón from the Unit of Flow Cytometry of the Center of Scientific Instrumentation (CIC) of the University of Granada (Spain) for his technical support.

The authors have declared no conflict of interest.

\section{References}

[1] Gabbiani, C., Magherini, F., Modesti, A., Messori, L. et al., Proteomic and metallomic strategies for understanding the mode of action of anticancer metallodrugs. Anticancer Agents Med. Chem. 2010, 10, 324-327.

[2] Urbani, A., Castagnola, M., Fasano, M., Bini, L. et al., Digital and analogical reality in proteomics investigation. Mol. Biosyst. 2013, 9, 1062-1063.

[3] Gamberi, T., Puglia, M., Bianchi, L., Gimigliano, A. et al., Evaluation of SCO1 deletion on Saccharomyces cerevisiae metabolism through a proteomic approach. Proteomics 2012, 12, 1767-1780.

[4] Urbani, A., Modesti, A., Timperio, A. M., Bini, L. et al., Integrative proteomics: perspective in complex system interpretation. Mol. Biosyst. 2012, 8, 951-952.

[5] Tsai, Y. Y., Huang, Y. H., Chao, Y. L., Hu, K. Y. et al., Identification of nanogold particle-induced endoplasmic 
reticulum stress by omic techniques and systems biology analysis. ACS Nano 2011, 5, 9354-9369.

[6] Ge, Y., Bruno, M., Wallace, K., Winnik, W., Prasad, R. Y., Proteome profiling reveals potential toxicity and detoxification pathways following exposure of BEAS-2B cells to engineered nanoparticle titanium dioxide. Proteomics 2011, 11, 2406-2422.

[7] Duncan, R., The dawning era of polymer therapeutics, Nat. Rev. Drug Discov. 2003, 2, 347-360.

[8] Zhang, L., Gu, F. X., Chan, J. M., Wang, A. Z. et al., Nanoparticles in medicine: therapeutic applications and developments. Clin. Pharm. Ther. 2008, 83, 761-769.

[9] Bae, K. H., Chung, H. J., Parkc, T. G., Nanomaterials for cancer therapy and imaging. Mol. Cells 2011, 31, 295-302.

[10] Farokhzad, O. C., Langer, R., Nanomedicine: developing smarter therapeutic and diagnostic modalities. Adv. Drug Deliv. Rev. 2006, 58, 1456-1459.

[11] Harries, M., Ellis, P., Harper, P., Nanoparticle albumin-bound paclitaxel for metastatic breast cancer. J. Clin. Oncol. 2005, 23, 7768-7771.

[12] Alexander, L. M., Pernagallo, S., Livigni, A., Sánchez-Martín, R. M. et al., Investigation of microsphere-mediated cellular delivery by chemical, microscopic and gene expression analysis. Mol Biosyst. 2010, 6, 399-409.

[13] Tsakiridis, A., Alexander, L. M., Gennet, N., Sànchez-Martín, R. M. et al., Microsphere-based tracing and molecular delivery in embryonic stem cells. Biomaterials 2009, 30, 58535861.

[14] Borger, J. G., Cardenas-Maestre, J. M., Zamoyska, R., Sànchez-Martín, R. M., Novel strategy for microspheremediated DNA transfection. Bioconjug. Chem. 2011, 22, 1904-1908.

[15] Cardenas-Maestre, J. M., Panadero-Fajardo, S., Perez-Lopez, A. M., Sànchez-Martín, R. M., Sulfhydryl reactive microspheres for the efficient delivery of thiolated bioactive cargoes. J. Mater. Chem. 2011, 21, 12735-12743.

[16] Yusop, R. M., Unciti-Broceta, A., Johansson, E. M. V., Sànchez-Martín, R. M. et al., Palladium-mediated intracellular chemistry. Nat. Chem. 2011, 3, 239-243.

[17] Unciti-Broceta, A., Johansson, E. M. V., Yusop, R. M., Sànchez-Martín, R. M. et al., Synthesis of polystyrene microspheres and functionalization with $\mathrm{Pd}(0)$ nanoparticles to perform bioorthogonal organometallic in living cells. Nat. Protoc. 2012, 7, 1207-1218.
[18] Sànchez-Martín, R. M., Muzerelle, M., Chitkul, N., How, S. E. et al., Bead-based cellular analysis, sorting and multiplexing. Chem. Bio. Chem. 2005, 6, 1341-1345.

[19] Magherini, F., Gamberi, T., Pietrovito, L., Fiaschi, T. et al., Proteomic and Carbonylation Profile Analysis of Rat Skeletal Muscles following Acute Swimming Exercise. PLoS One, 2013, 8, e71839.

[20] Guidi, F., Puglia, M., Gabbiani, C., Landini, I. et al., 2D-DIGE analysis of ovarian cancer cell responses to cytotoxic gold compounds. Mol. Biosyst. 2012, 8, 985-993.

[21] Gamberi, T., Rocchiccioli, S., Papaleo, M. C., Magherini et al., RND-4 efflux transporter gene deletion in Burkholderia cenocepacia J2315: a proteomic analysis. J. Proteome Sci. Comput. Biol. 2013, 1-14, ISSN: 2050-2273.

[22] Candiano, G., Bruschi, M., Musante, L., Santucci, L. et al., Blue silver: a very sensitive colloidal Coomassie G-250 staining for proteome analysis. Electrophoresis 2004, 25, 1327-1333.

[23] Armeni, T., Ercolani, L., Urbanelli, L., Magini, A. et al., Cellular redox imbalance and changes of protein S-glutathionylation patterns are associated with senescence induced by oncogenic H-Ras. PLoS ONE 2012, 7, e52151.

[24] Chillà, A., Magherini, F., Margheri, F., Laurenzana, A. et al., Proteomic identification of VEGF-dependent protein enrichment to membrane caveolar-raft microdomains in endothelial progenitor cells. Mol. Cell. Proteomics 2013, 12, 1926-1938.

[25] Mi, H., Muruganujan, A., Thomas, P. D., PANTHER in 2013: modeling the evolution of gene function, and other gene attributes, in the context of phylogenetic trees. Nucleic Acids Res. 2013, 41, 377-386.

[26] Antonov, A. V., BioProfiling.de: analytical web portal for high-throughput cell biology. Nucleic Acids Res. 2011, 39, 323-327.

[27] Antonov, A. V., Schmidt, E., Dietmann, S., Krestyaninova, M. et al., R spider: a network-based analysis of gene lists by combining signaling and metabolic pathways from Reactome and KEGG databases. Nucleic Acids Res. 2010, 38, 118-123.

[28] Gamberi, T., Magherini, F., Bini, L., Messori, L. et al., New insights into the molecular mechanisms of selected anticancer metal compounds through bioinformatic analysis of proteomic data. J. Proteomics Bioinform. 2013, S6, 006. doi:10.4172/jpb.S6-006. 